9960

PPPL-2818

UC-422,427
PREPARED FOR THE U.S. DEPARTMENT OF ENERGY, UNDER CONTRACT DE-AC02-76-CHO-3073

PPPL-2818
THREE-DIMENSIONAL TOKAMAK EQUILIBRIA

IN THE PRESENCE OF RESONANT FIELD ERRORS

BY

\author{
A. REIMAN AND D. MONTICELLO
}

January 1992
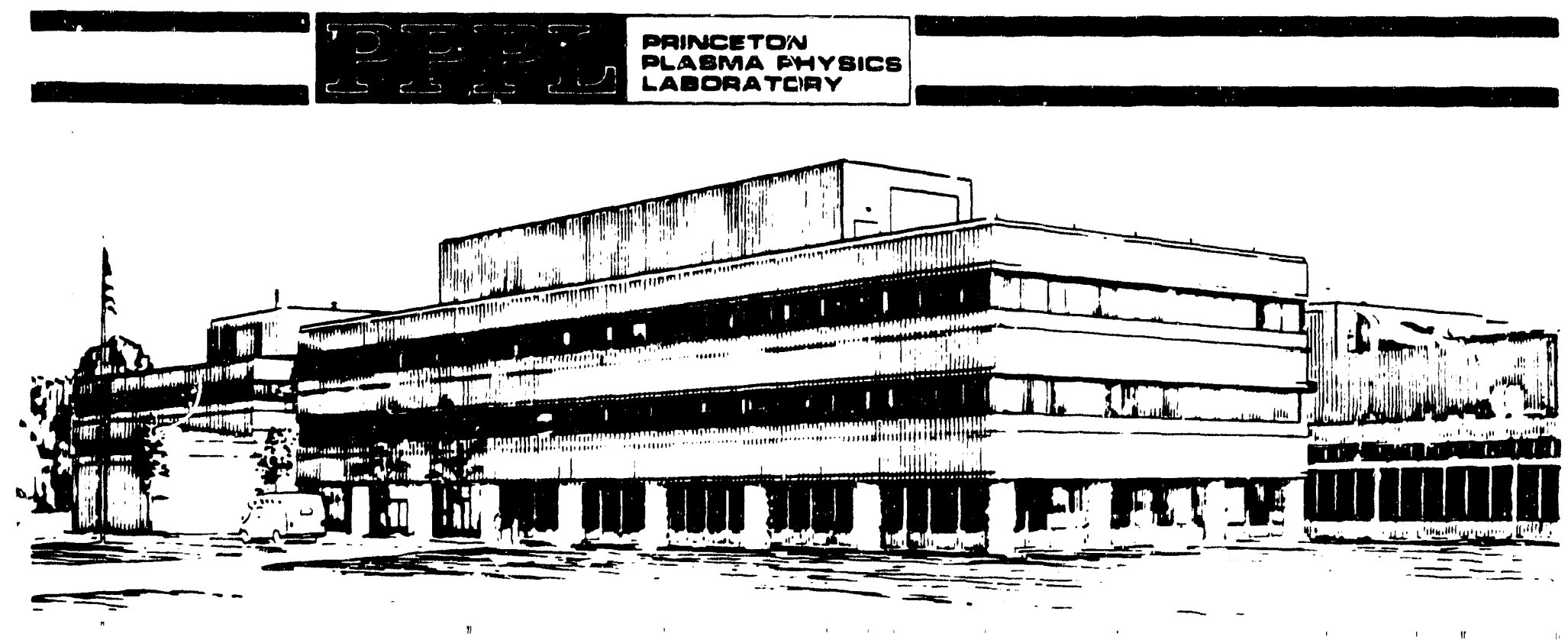


\section{NOTICE}

This report was prepared as an account of work sponsored by an agency of the United States Government. Neither the United States Govern.nent nor any agency thereof, nor any of their employees, makes any warranty, express or implied, or assumes any legal liability or responsibility for the accuracy, completeness, or usefulness of any information, apparatus, product, or process disclosed, or represents that its use would not infringe privately owned rights. Reference herein to any specific commercial produce, process, or service by trade name, trademark, manufacturer, or otherwise, does not necessarily constitute or imply its endorsement, recommendation, or favoring by the United States Government or any agency thereof. The views and opinions of authors expressed herein do not necessarily state or reflect those of the United States Government or any agency thereof.

\section{NOTICE}

This report has been reproduced directly from the best available copy.

Available to DOE and DOE contractors from the:

Otfice of Scientific and Technical Information

P.O. Box 62

Oak Ridge, TN 37831 ;

Prices available from (615) 576-8401.

Available to the public from the:

National Technical Information Service

U.S. Department of Commerce

5285 Port Royal Road

Springfield, Virginia 22161

$703-487-4650$ 
PPPL- -2818

DE92 006647

November 26, 1991

\title{
Three-Dimensional Tokamak Equilibria in the Presence of Resonant Field Errors
}

\author{
A. Reiman and D. Monticello \\ Princeton Plasma Physics Laboratory \\ Princeton, N. J. 08543
}

\begin{abstract}
Numerical solutions are described for three-dimensional MHD equilibria in the presence of resonant magnetic field perturbations. The effects of a realistic spectrum of resonant field errors are calculated for a range of current profiles. It is found that field errors of the magnitude existing in present day devices, and contemplated for future devices, can produce a set of magnetic islands occupying a significant fraction of the plasma cross-section.
\end{abstract}




\section{Introduction}

In this paper we describe numerical solutions for three-dimensional MHD equilibria in the presence of resonant magnetic field perturbations. Although the tokamak is nominally an axisymmetric device, present day tokamaks typically have nonaxisymmetric resonant field errors of order $\delta B / B \approx 10^{-4}$. We will see that perturbations of this magnitude can have a significant effect on the plasma equilibrium, producing magnetic islands that short-circuit the confinement properties of the magnetic field. (Measured error field magnitudes will be discussed in Sec. 2.)

The poloidal and toroidal mode numbers of a resonant perturbation, $(m, n)$, satisfy the resonance condition $m=n q$ for a rational surface in the plasma with safety factor $q$. Such a perturbation produces islands whose width scales as $|\delta B / B|^{1 / 2}$, so that the equilibrium is sensitive to perturbations of relatively small amplitude. As we will see, the sensitivity to resonant perturbations is further enhanced by the plasma response, which can amplify the field errors.

The numerical calculations for this paper were performed using the threedimensional equilibrium code PIES[1,2], which is capable of handling islands and stochastic regions. The code self-consistently flattens current and pressure profiles in islands and stochastic regions when they appear. We have specialized to zero $\beta$ to study the effect of the current profile on the selfconsistent plasma response. A previous paper has studied this issue from a purely analytical point of view, assuming tokamak ordering and narrow islands.[3] A review paper has presented an overview of field error effects, including a few illustrative numerical calculations.[4] This paper presents a more systematic set of numerical computations.

Our equilibrium calculations assume zero fluid velocity. We will have something to say about the effects of fluid velocity in Sec. 5 .

We will present numerical solutions for a range of current profiles. It is to be expected that the character of sur nonaxisymmetric equilibrium solutions will be strongly affected by the tearing stability properties of our current profiles. Let us first review the relation that has been established between equilibrium and stability properties for analytical solutions in a cylinder.[3] Figures 1 and 2 characterize the solutions in the absence and in the presence of an error field, respectively. The radial component of the resonarit magnetic 
field at the rational surface, $B_{r}\left(r_{s}\right)$, is plotted as a function of a profile parameter, with $\Delta^{\prime}$ assumed to increase monotonically as a function of the parameter. (The island width is proportional to $\left|B_{r}\left(r_{s}\right)\right|^{1 / 2}$. We plot $B_{r}$ at the rational surface rather than the island width to retain phase information.)

Figure 1 shows the behavior of the equilibrium solutions in the absence of an error field. For $\Delta^{\prime}>0$, the cylindrically symmetric equilibrium is unstable. There are also equilibrium solutions corresponding to saturated tearing modes. As $\Delta^{\prime} \rightarrow 0$ from the right, the island width goes to zero. The point $\Delta^{\prime}=0$ corresponds to a bifurcation point of the solution.

In the presence of a nonaxisymmetric external perturbation, the solutions are as shown in Fig. 2. For $\Delta^{\prime}<0$, the equilibrium is now a nonsymmetric one with an island. For large $\Delta^{\prime}$ there are again three solutions. The external perturbation breaks the bifurcation at $\Delta^{\prime}=0$, so that the solution now consists of two independent branches. The solution for $\Delta^{\prime}<0$ goes smoothly into the locked mode solution for $\Delta^{\prime}>0$. This is the branch that we are interested in.

The generic behavior of the solutions follows from general arguments of bifurcation theory, [5] and does not depend on the details of the equations. In particular, we can expect that the generic features of the solutions that we have described above will not be affected by the addition of toroidicity. In the absence of an external perturbation, there is an axisymmetric solution. In the unstable regime, there are also nonaxisymmetric solutions corresponding to saturated tearing modes. As the growth rate of the tearing mode goes to zero, we can expect the saturated island width to go to zero. In the absence of a nonaxisymmetric external perturbation, the marginal stability point corresponds to a bifurcation point for the equilibrium solutions. The bifurcation point appears because of the presence of an underlying symmetry (axisymmetry) which is broken by the instability. The solution must be independent of the phase of the instability, giving rise to a bifurcation.

When a nonaxisymmetric external perturbation is imposed, the solutions with large islands in the unstable regime retain their character, so that for current profiles corresponding to tearing modes with large growth rate there are still three equilibrium solutions. In the presence of the perturbation, the stable axisymmetric equilibrium goes into a nonaxisymmetric equilibrium with an islard. We can expect this solution to go smoothly into the locked mode solution in the unstable regime. The underlying symmetry that 
produced the bifurcation at the marginal point has been broken.

In principle, we can calculate locked mode solutions by using our threedimensional equilibrium code to track the equilibrium solution from the stable regime into the unstable regime. In practice we find that PIES readily converges to solutions on the stable branch if initialized appropriately, so that it is not necessary to track from the stable regime if only a single solution is desired. Note from Fig. 2 that solutions on the stable branch are readily distinguished from those on the unstable branch by the phase of the island. The angular locations of the $\mathrm{O}$-points and $\mathrm{X}$-points are interchanged for the two branches. (Continuity implies that the phase remains the same as one moves along a given branch.)

Although we can solve the fully three-dimensional problem in a torus, it is also useful to look at solutions in a cylinder. Such solutions are helpful in understanding the physics, because the island width is tied directly to the radial component of the field $\left(w \propto\left|B_{r}\right|^{1 / 2}\right)$. A separate study of cylindrical solutions will also allow us to determine what effects are due to toroidal coupling. In addition, cylindrical geometry is convenient for systematic parameter scans because the absence of toroidal coupling reduces the number of Fourier modes required, and therefore reduces the computational expense. Section 3 presents numerical calculations in cylindrical geometry.

In Sec. 4 we present numerical calculations in toroidal geometry.

The correspondence of our results with experimental observations, and the practical implications of our results, are discussed in Sec. 5.

\section{Preliminaries}

In this section we describe the field error imposed as a boundary condition in our numerical solutions, and we relate it to field errors that are believed to exis $\imath$ in present day tokamaks. We also describe the set of current profiles studied in our numerical calculations. In addition, we give a brief overview of the PIES code.

Nonaxisymmetric error fields are produced in present day tokamaks by such things as finite tolerances in installation of the poloidal and toroidal field coils, the presence of bus bars, etc. Typical magnitudes of such fields are $\delta B / B \approx 10^{-4}$ for the low order Fourier components. In JET, the $m=2$, $n=1$ Fourier component of the field error is believed to be of order 1 Gauss 
at the $q=2$ surface, and to be caused by the toroidal bus bars.[6] In ASDEX, the $(2,1)$ Fourier component of the error field is believed to be about one or two Gauss, [7] and to be caused by the finite tolerances in the installation of the toroidal field coils. In DIII-D, the contribution of the PF coils to the field error has been measured, and is found to have an $m=2, n=1$ amplitude of about 2 Gauss. [8]

On the basis of the experimental observations and theoretical calculations, the BPX project adopted a tentative field error tolerance of the form

$$
\sum_{1 \leq m / n \leq 5} \frac{1}{n}\left(\frac{r n B_{r m n}}{B}\right)^{1 / 2}<E,
$$

with $E \approx .05$.[9] Preliminary studies indicated that this would produce a very stringent tolerance on coil placement, $[9]$ and would also place a stringent constraint on some of the PF coil winding patterns. It was decided to incorporate error field trim coils in the proposed design for the purpose of tuning out residual field errors.

For our numerical equilibrium solutions, we calculate the imposed error field from a small shift and elliptical deformation of a nearly circular poloidal field coil. The coil is placed at $R=6 a$ (where $R$ is the major radius and $a$ the minor radius), which is typical for the large vertical field coil in a tokamak. The coil current and shift were chosen to approximately reproduce the $n=1$ error field spectrum which had been reported for DIII-D on the basis of known PF coil installations errors.[10] (Since this work was begun, the PF coil field errors on DIII-D have been directly measured,[8] and the field error amplitude believed to exist in the device has been revised upward by about a factor of 2.) The shift is $0.5 \%$, and the current is approximately that required by the Shafranov formula for radial force balance.[11] The elliptical deformation was also taken to be .5\%. This is comparable to the maximum measured elliptical deformation of the TFTK poloidal field coils. The resulting $m=3$, $n=2$ field error is very close to that measured on DIII-D, while the imposed field errors for $n=2$ and higher $m$ fall off more rapidly than those measured on DIII-D. In specifying our boundary condition, we retain only resonant Fourier components of the nonaxisymmetric field. The values of $B_{r n m} / B$ at the boundary for $n=1, m=2$ to 5 are $5.7 \times 10^{-5}, 3.7 \times 10^{-5}, 2.0 \times 10^{-5}$, and $1.0 \times 10^{-5}$. For $n=2$, only the odc $m$ Fourier components are retained in the boundary condition, since the even $m$ components only produce small 
modifications of the $n=1$ resonances. The amplitudes for $n=2, m$ odd from $m=3$ to $m=9$ are $3.3 \times 10^{-5}, 1.0 \times 10^{-5}, 2.0 \times 10^{-6}$, and $3.3 \times 10^{-7}$.

In addition to the resonant field error, tokamaks also have a nonaxisymmetric component of the magnetic field produced by the discreteness of the toroidal field coils. The magnitude of this "field ripple" is typically much larger than the magnitude of the field error we are considering, but it is nonresonant, and therefore does not produce islands. We neglect this nonresonant part of the nonaxisymmetric magnetic field in the calculations described in this paper.

Now we turn to a description of our current profiles. We specify

$$
\sigma \equiv \mathbf{j} \cdot \mathbf{B} / B^{2}
$$

For a zero $\beta$ equilibrium, this quantity is constant along field lines. On the good flux surfaces, $\sigma$ is a function of the flux surface. In the stochastic regions, $\sigma$ must be a constant. In the islands, we are free to choose $\sigma$ to be any function of the flux surfaces. We take $\sigma$ to be flat in the islands.

Our calculations use the set of current profiles investigated by Furth et al.[12] We set

$$
\sigma(\rho)=\sigma_{0}\left[1+\left(\rho / \rho_{0}\right)^{2 \gamma}\right]^{-(1+1 / \gamma)} .
$$

This set of current profiles has been used extensively for tearing mode studies. (Our $q$ profiles will differ somewhat from that of these previous studies because of the effects of toroidicity, and because of differences in the assumed aspect ratios.) Equation (2) contains three free parameters, $\sigma_{0}, \rho_{0}$ and $\gamma$, allowing us to independently control the $q$ on axis, the "peakedness" of the current profile, and the location of the rational surface. In the absence of islands and stochastic regions, $\rho$ is defined to be a flux surface label that measures the distance along the midplane from the magnetic axis to the outer edge of the corresponding flux surface. When islands and stochastic regions are present, we integrate along the midplane from the magnetic axis to the edge of the computational domain, defining

$$
\frac{d \rho}{d R}= \begin{cases}0 & \text { in islands and stochastic regions } \\ 1 & \text { elsewhere. }\end{cases}
$$

We extend $\rho$ off the midplane by taking it to be constant on flux surfaces. With this definition $\rho$, and therefore $\sigma$, is constant in the islands and the 
stochastic regions. (Sykes and Wesson have used a similar method for specifying current profiles in their calculations of cylindrical equilibria with islands.[13]) When islands appear, we adjust the values of $\sigma_{0}$ and $\rho_{0}$ to keep the $q$ on axis and the total current fixed. In cylindrical geometry, this also fixes $q$ at the edge.

To calculate a three-dimensional equilibrium solution, the PIES code begins with an initial guess for the magnetic field. For this purpose, we typically use an analytical, cylindrically symmetric equilibrium solution. We can also initialize with the calculated solution for a different set of parameters, allowing efficient tracking of the equilibrium solution as a function of a continuously varying parameter. The code proceeds by iteratively improving the guess for the field. At each iteration, the code follows a set of field lines filling the volume of interest. A diagnostic determines where the islands and stochastic regions are. Magnetic coordinates are calculated for the good flux surfaces. These calculations allow the code to determine the spatial distribution of current from the given $\sigma$ profile. The magnetic field is then updated by solving Ampere's law,

$$
\nabla \times \mathbf{B}=\mathbf{j},
$$

in the presence of those currents. The boundary condition specifies the normal component of the magnetic field on the boundary of the computational domain. The code continues the iteration procedure until the magnetic field converges. The algorithm can be summarized by the equation

$$
\nabla \times \mathbf{B}^{n+1}=\mathbf{j}\left(\mathrm{B}^{n}\right) \text {. }
$$

The magnetic field at the $(n+1)$ 'st step is calculated by solving Ampere's law, using a current which is a complicated nonlinear function of the magnetic field at the $n^{\prime}$ th step. In this form, it is clear that the mithod is closely related to the well-known Picard iteration scheme for solving the Grad-Shafranov equation in two dimensions. This iterative scheme for solving the threedimensional MHD equilibrium equations was proposed by Grad[14] and by Spitzer[15] in the 1950's.

\section{Numerical Calculations in Cylindrical Geometry}

In this section we describe the resulis of numerical calculations in cylindrical geometry. Although the PIES code can handle toroidal geometry (and 
toroidal calculations will be presented in Sec. 4), cylindrical calculations are useful for clarifying the physics, because the island width is tied directly to the radial component of the field. A separate study of cylindrical solutions also allows us to determine what effects are due to toroidal coupling. In addition, cylindrical geometry is convenient for systematic parameter scans, because the absence of toroidal coupling reduces the number of Fourier modes required, and therefore reduces the computational expense.

Before turning to a more systematic study, we first illustrate the effect we are looking at for a set of particularly simple cases. We assume helical symmetry, so that there is only a single resonant mode. In that case, the interpretation of the results is not complicated by mode coupling effects. We look at a set of helical solutions in a long, thin cylinder $\left(R_{0} / a=20\right)$ for an $m=2, n=1$ mode, taking $\gamma=4$ and $\rho_{0} / a=.6$ in Eq. (2), and choosing $\sigma_{0}$ so that $q$ on axis is 1.05 . The mode is unstable for this choice of parameters.

Figure $i$ shows the equilibrium value of $R_{0} B_{r} / a B_{\phi}$ as a function of $r / a$ for three different levels of error field. The error field in each case is specified by fixing $B_{r}$ at the boundary. Conventional tearing mode calculations assume that $B_{r} \rightarrow 0$ at the boundary. The curve with $B_{r}=0$ at $r=a$ corresponds to the saturated tearing mode in the absence of an error field. The corresponding normalized value of $B_{r}$ at the rational surface is $1.6 \times 10^{-4}$, which gives an island width of about $5 \%$.

In addition to $B_{r}=0$ at the edge, we also show cases with normalized $m=2, n=1 B_{r}$ values of $10^{-4}$ and $3 \times 10^{-4}$ at the edge. In the absence of a self-consistent plasma response, $B_{r}$ would decay linearly away from the boundary. For $R_{0} B_{r}(r=a) / a B_{\phi}=10^{-4}$, for example, the vacuum error field would have a magnitude at the rational surface about half that of the saturated mode. Instead, we find that the self-consistent plasma response strongly amplifies the error field; so that the field at the rational surface is about 5 times that at the edge, and about 3 times what it is in the absence of an error field. Multiplying the field at the edge by a factor of 3 gives little change in the shape of the eigenfunction, so that the field at the rational surface is now about 4 times what it is at the boundary, and about 8 times what it is in the absence of an error field.

Our helical calculations show that MHD equilibria can be sensitive to the presence of small nonaxisymmetric perturbations. The amplification is sufficient to suggest that error fields of the magnitude that exist in present 
devices can produce significant islands. Now we turn to three-dimensional calculations, and we study the dependence of the island width on the current profile. The current profile parameter, $\gamma$, is varied over a range from $\gamma=1$ to $\gamma=3$. We keep $q_{0}$ fixed at a value of 1.1 , and we fix $\rho_{0} / a=0.6$. We do these calculations in a fatter cylinder, $R_{0} / a=3.0$. For these calculations we also impose the more realistic spectrum of error fields described in Sec. 2.

Figures 4 and 5 show the calculated locations of the island edges as a function of $\gamma$ without and with an error field. An open circle indicates the inner edge of an island, and a filled circle indicates an outer edge. Each island is labeled with its corresponding $m / n$. These calculations employed 60 radial grid surfaces, and islands smaller than the radial grid size were neglected.

Figure 4 shows that the current profile gets increasingly unstable as we increase $\gamma$. The saturated width of the $2 / 1$ island goes up. Islands appear at the $3 / 1$ and $3 / 2$ rational surfaces when $y=2.5$. Previous tearing mode calculations have also shown increasing instability with increasing $\gamma$, and have seen a tendency for disruptions as $\gamma$ approaches 4.[16] (However, these disruption calculations were done in the limit of a narrow cylinder, while our calculations take $R / a=3$.) From these previous calculations we know that the flattening of the current profile caused by the presence of the $2 / 1$ island plays a major role in destabilizing the $3 / 2$ mode.

Figure 5 shows that in the presence of the field error, the islands are larger and more numerous. As the $2 / 1$ island width goes up, the effect of the $2 / 1$ error field is actually decreasing. This is accompanied by an increasing sensitivity to the presence of the $n=2$ Fourier components of the error field. Overall, the totai island width for all the values of $\gamma$ is considerably larger in the presence of the field error than in its absence. The decreasing sensitivity to the $2 / 1$ error field at large $\Delta^{\prime}$ has been seen also in analytical calculations,[3] and is to be expected on physical grounds. When the radial magnetic field associated with a saturated island is sufficiently large relative to the error field, we can expect the error field to have only a small effect on the saturated island width.

Figure 6 shows the Poincare plot for $\gamma=3$ with error fields. Note that we show only the region $r>.4$, corresponding to the region shown in figures 4 and 5 . There are no islands in the region $r<.4$. The figure shows a large fraction of the outer half of the plasma occupied by islands. We see higher order $n=3$ islands beginning to emerge. We have not included $n=3$ terms 
in our error field. We expect that such terms could have a large effect on the $\gamma=3$ islands near the plasma edge. As we increase $\gamma$ to 3 and beyond, the calculations become increasingly expensive berause of the need to retain increasing numbers of Fourier modes. The equilibria also become increasingly uninteresting, in the sense that the plasma becomes poorly confined in the presence of the large number of modes.

In the next section we look at the effects of toroidicity on our results.

\section{Numerical Calculations in Toroidal Geometry}

In the previous section we described a series of three-dimensional equilibrium calculations, with and without field errors, for five different values of $\gamma$ ranging from $\gamma=1$ to $\gamma=3$. In this section we look at toroidal effects. For this purpose, we have calculated toroidal three-dimensional equilibrium solutions for $\gamma=1$ and $\gamma=1.5$. As in the cylindrical runs we fix $\rho_{0} / a=.6$ and $R / a=3$, and we adjust $\sigma_{0}$ to give a $q$ on axis of about 1.1. The resulting $q$ profile is slightly higher at the edge in a torus than it is in a cylinder. As in the series of cylindrical runs, we impose the field error spectrum described in Sec. 2.

Figure 7 shows the Poincare plot for $\gamma=1$ in the absence of field errors. The $2 / 1$ island is approximately the same width as in cylindrical geometry. There is now, in addition, a $3 / 1$ island, presumably driven by the toroidal coupling to the $2 / 1$ mode.

Figure 8 shows what happens in the presence of field errors. As for the cylindrical solution, the islands are larger and more numerous than in the absence of field errors. The $n=1, m>1$ islands are somewhat larger than in the cylindrical case, and $n=2$ islands are now visible. The total island width across the midplane is about $23 \%$ of the minor radius.

Figures 9 is a Poincare plot for $\gamma=1.5$ in the absence of field errors. The $2 / 1$ and $3 / 1$ islands are larger than for $\gamma=1$, and $3 / 1$ and $3 / 2$ islands are now visible. This is to be contrasted with the cylindrical case, where only the $2 / 1$ island was present.

Figure 10 shows the effect of field errors for $\gamma=1.5$. The islands are again larger and more numerous. Higher order islands are now visible with $n$ as high as 3 . We would expect that the plasma is getting close to a disruption. 
We find for both values of $\gamma$ that the $2 / 1$ island is noi strongly affected by toroidicity. Toroidal coupling does lead to increased island widtns for $n=1$, $m>2$. The toroidal calculations also show larger island widths for $n>1$.

\section{Discussion}

We have numerically calculated the effects of a realistic spectrum of resonant field errors on three-dimensional equilibria for a range of current profiles. (The magnitude of our field error is actually somewhat smaller than that believed to exist on present day devices.) For all of our current profiles $q_{0} \approx 1.1$ and $q_{\text {edge }}<5$. The $m / n=2 / 1$ mode is tearing unstable, and for $R / a=3$ we observe only a modest error field effect on the saturated island, with an increase in width of at most fifty percent corresponding to about a factor of two enhancement of the resonant field at the rational surface. (This is to be contrasted with the helical calculation in a long, thin cylinder, presented at the beginning of Sec. 3, where amplification of the field by a factor of four to tive is observed.) The most important effect of field errors observed in these calculations is an increase in the width and number of $n=1, m>2$ islands and $n>1$ islands, so that a significantly larger fraction of the plasma is occupied by islands.

We can interpret these results in terms of previous tearing mode stability studies, and in terms of our analytical error field studies.[3] It is well known that the flattening of the current profile produced by a magnetic island stabilizes the corresponding mode, and is what causes it to saturate, but destabilizes other modes.[17,16,18] We have found that the addition of nonaxisymmetric field errors produces a modest effect on island widths well above marginal instability, but that the error field can be strongly amplified in the neighborhood of marginal stability (either just above or just below marginal stability). These effects, taken together, suggest that field errors will make themselves felt by producing a large set of islands at many rational surfaces.

Our calculations show that field errors of the magnitude that exists in present day devices, and is contemplated for future devices, can significantly affect three-dimensional equilibrium. The three-dimensional equilibrium calculations neglect the effect of toroidal plasma rotation. To assess the practical implications of our calculations, we need to take those effects into account. 
Rotation of an island relative to the stationary external field error shields the island region from influence by the field error. The currents which shield the resonant layer from the external field are regenerated by the rotation, $\mathrm{it}_{\mathrm{t}}$ the same manner in which a resistive external shell can maintain its stabilizing effect if the plasma rotates toroidally.[19] (The rotation time scale in both cases needs to be short compared to the relevant resistive diffusion time scale.)

A rotating magnetic island feels a torque due to the nonaxisymmetric error field, and due to the nonaxisymmetric field produced by currents induced in external resistive conductors. When an unstable island grows to suffciently large width, the torque can be large enough to stop the rotation of the island, and lock it on to the external field.[20] Toroidal rotation measurements typically show that the rotation velocity then goes to zero everywhere in the plasma.[6] At this point the effects described in this paper come into play.

When an unstable tearing mode locks onto the external error field, our calculations show that the saturated island width will be increased by the influence of the error field. Even more important with the plasma now stationary, a large set of rational surfaces becomes susceptible to the influence of field errors, and many stationary islands appear. These conclusions are consistent with a belief among many experimentalists that locked modes tend to disrupt more readily than rotating tearing modes (although we are not aware of any statistical studies that test this belief).

Locked modes also appear in low density ohmic discharges in the absence of any detectable precursor instability.[21] This appears to occur when the viscous drag on the island induced by the error field becomes sufficiently small to be overcome by the torque exerted by the field error.[22] Here, too, a serious deterioration of confinement is generally observed, even though the vacuum island width induced by the reson : field error is small.

A recent theory of low density locked modes finds that error fields penetrate more easily in large devices,[23] so that field errors of order $\delta B / B \approx$ $10^{-5}$ will be sufficient to cause locking in ITER. The penetration of field errors of this magnitude suggests that rotation effects will no longer be of significance for startup on such large devices. The significant issues will relate to the effects described in this paper.

There is at least one other situation where the effects described in this pa- 
per need to be taken into account. The use of time varying nonaxisymmetric fields is sometimes suggested for the purpose of sweeping divertor nonaxisyinmetries across the divertor plates in the toroidal direction. The fields required for this purpose must be large enough to dominate the error fields, and may cause mode locking in a rotating frame. As long as the time scale for rotation is slow compared to the Alfven time scale, the three-dimensional equilibrium considerations of this paper will apply in a rotating frame. Mode locking of externally induced islands in a rotating frame has even been suggested as a means of injecting momentum into a plasma.[24] Here one clearly needs to be concerned about the resulting equilibrium island widths in the rotating frame.

Our discussion of plasma rotation leads us to the conclusion that the consideration of field error amplification effects can be largely decoupled from plasma rotation issues. For low density ohmic startup of large tokamaks such as ITER, calculations indicate that the penetration threshold of field errors is quite small, and rotation can be safely neglected in applying the theory of this paper. For the evolution of rotating, unstable tearing modes, field error amplification effects can be neglected. When the mode locks, the subsequent evolution of the plasma can generally be calculated without regard to rotation effects. The effects of a rotating externally imposed nonaxisymmetric field can similarly be calculated, when islands lock, in a rotating reference frame, with no further regard for rotation effects.

We conclude finally that field error effects will become increasingly important in large devices such as ITER. These effects should be taken into account in determining construction tolerances, and possibly in guiding the design of nonaxisymmetric trim coils for tuning out residual field errors.

\section{ACKNOWLEDGMENT}

We are grateful to R. Goldston, R. J. LaHaye, G. H. Neilson, and J. T. Scoville for useful discussions. This work was supported by the United States Department of Energy under Contract DE-AC02-76-CHO-3073. 


\section{References}

[1] A. H. Reiman and H. S. Greenside, Comput. Phys. Commun. 43, 157 (1986).

[2] A. H. Reiman and H. S. Greenside, J. Comput. Phys. 87(2), 349-365 (April 1990).

[3] A. Reiman, Phys. Fluids 3(9), 2617 (September 1991).

[4] A. Reiman and D. Monticello, Phys. Fluids 3(8), 2230 (August 1991).

[5] G. Ioos and D. D. Joseph, Elementary Stability and Bifurcation Theory. Springer-Verlag, New York, second edition, 1990.

[6] J. A. Snipes, D. J. Campbell, T. C. Hender, M. V. Hellermann, and H. Weisen, Nucl. Fusion 30(2), 205-218 (1990).

[7] H. Zohm, A. Kallenbach, H. Bruhns, G. Fussmann, and O. Klueber, Europhys. Lett. 11(8), 745-750 (1990).

[8] R. J. L. Haye and J. T. Scoville, Review of Scientific Instruments (submitted for publication) (1991).

[9] R. J. Goldston, G. H. Neilson, D. B. Batchelor, G. Bateman, M. G. Bell, D. N. Hill, W. A. Houlberg, S. C. Jardin, S. S. Medley, N. Pomphrey, M. Porkolab, R. O. Sayer, D. J. Sigmar, D. P. Stotler, D. J. Strickler, M. Ulrickson, R. E. Waltz, P. T. Bonoli, B. Braams, J. Brooks, M. D. Carter, H. F. Dylla, R. C. Englade, R. H. Goulding, J. R. Haines, D. J. Hoffman, J. C. Hosea, E. F. Jaeger, J. L. Johnson, S. M. Kaye, C. Kessel, J. Kinsey, A. Kritz, R. J. LaHaye, R. A. Langley, J. Manickam, T. K. Mau, J. Milovitch, W. A. Peebles, C. K. Phillips, R. Pillsbury, R. Prates, A. Reiman, T. Rognlien, P. M. Ryan, J. E. Scharer, C. E. Singer, G. R. Smith, R. D. Stambaugh, D. W. Swain, J. S. Tolliver, J. R. Wilson, K. Wilson, K. M. Young, and J. J. Yugo, Burning Plasma Experiment Design Description, Fusion Technology (to be published).

[10] T. Scoville, R. LaHaye, A. Kellman, T. Osborne, R. Stambaugh, E. Strait, and T. Taylor, Bull. Am. Phys. Soc. 34(9), 2118 (October 1989). 
[11] V. D. Shafranov, Reviews of Plasma Physics, volume 2, pages 103-151, Consultants Bureau, New York, 1966.

[12] H. P. Furth, P. H. Rutherford, and H. Selberg, Phys. Fluids 16, 1054 (1973).

[13] A. Sykes and J. Wesson, in Plasma Physics and Controlled Nuclear Fusion Research, Proceedings of the 8th International Conference, Brussels, 1980, (IAEA, Vienna, 1981), Vol. I, p. 237.

[14] H. Grad and H. Rubin, in Proc. of the Second United Nations International Conf. on the Peaceful Uses of Atomic Energy, 1958, (United Nations, Geneva, 1958) 31, p. 190.

[15] L. Spitzer, Phys. Fluids 1, 253 (1958).

[16] B. V. Waddell, B. Carreras, H. R. Hicks, and J. A. Holmes, Phys. Fluids 22, 896 (1979).

[17] R. B. White, D. A. Monticello, M. N. Rosenbluth, and B. V. Waddell, Phys. Fluids 20, 800 (1977).

[18] R. G. Kleva, J. F. Drake, and A. Bondeson, Phys. Fluids 27, 769 (1984).

[19] T. H. Jensen and M. S. Chu, J Plasma Phys 30, 57 (1983).

[20] M. F. F. Nave and J. A. Wesson, Nucl. Fusion 30, 2575 (1990).

[21] J. T. Scoville, R. J. L. Haye, A. G. Kellman, T. H. Osborne, R. D. Stambaugh, E. J. Strait, and T. S. Taylor, Nuclear Fusion 31, 875 (1991).

[22] R. Fitzpatrick and T. C. Hender, Physics of Fluids B 3, 644 (1991).

[23] A. W. Morris, R. Fitzpatrick, T. C. Hender, T. N. Todd, R. Bamford, C. A. Bunting, P. G. Carolan, D. C. Reddy, R. D. Durst, T. Edlington, S. J. Fielding, J. Ferreira, P. S. Haynes, J. Hugill, I. Jenkins, S, J. Manhood, P. Nicholson, B. Parham, D. C. Robinson, K. Stammers, M. Valovic, G. Vayakis, R. J. L. Haye, and J. T. Scoville, in Controlled Fusion and Plasma Physics (Proc. 18th Eur. Conf. Berlin, 1991), Vol. 15C, Pt. II, page 61, European Physical Society, 1991. 
[24] T. H. Jensen and A. W. Leonard, in International Sherwood Fusion Conference, page 2B4, Seattle, Washington, April 1991. 


\section{Figuies}

Fig. 1. Schematic plot of $B_{r}\left(r_{s}\right)$ as a function of a profile parameter in the absence of field errors. We assume that $\Delta^{\prime}$ increases monotonically with the profile parameter.

Fig. 2. Behavior of $B_{r}\left(r_{s}\right)$ in the presence of an error field. The dashed line indicates its behavior in the absence of field errors.

Fig. 3. Normalized radial field for a helical equilibrium solution with several different values of the error field.

Fig. 4. Calculated locations of island edges as a function of $\gamma$ for a cylindrical plasma in the absence of error fields. Open circles indicate the inner island edges, and filled circles indicate the other edges. Labels on the right of the figure indicate $m / n$ for each island, where $m$ is the poloidal mode number and $n$ is the toroidal mode number.

Fig. 5. Island edges as a function of $y$ in the presence of error fields.

Fig. 6. Poincare plot for $\gamma=3$ cylindrical solution with error fields.

Fig. 7. Poincare plot for a toroidal solution with $R / a=3, \gamma=1$ and no error field.

Fig. 8. Poincare plot for a toroidal solution with $R / a=3, \gamma=1$ and error field as described in the text.

Fig. 9. Poincare plot for a toroidal solution with $\gamma=1.5$ and no error field.

Fig. 10. Poincare plot for a toroidal solution with error field for $\gamma=1.5$. 


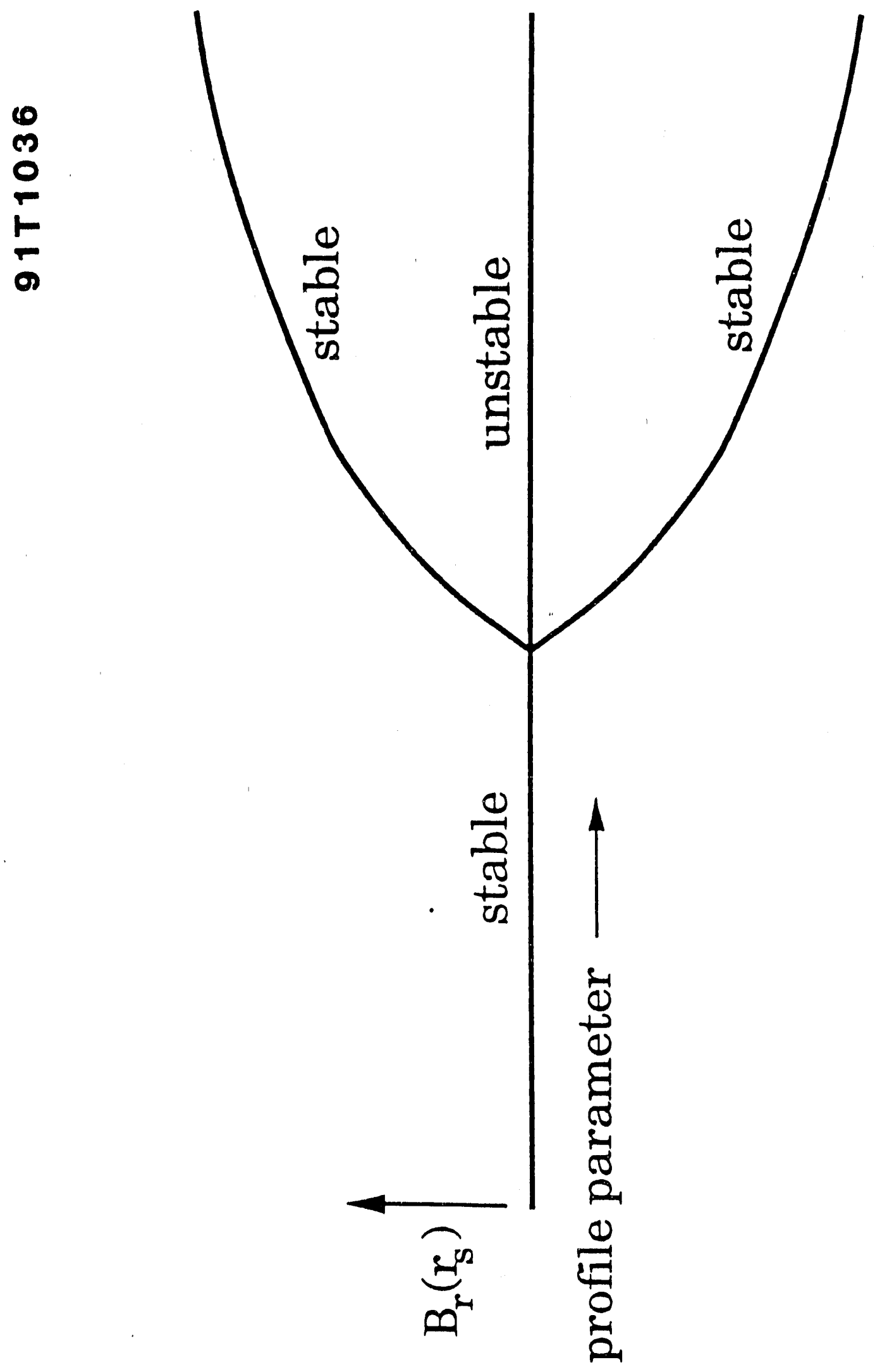


$\checkmark$

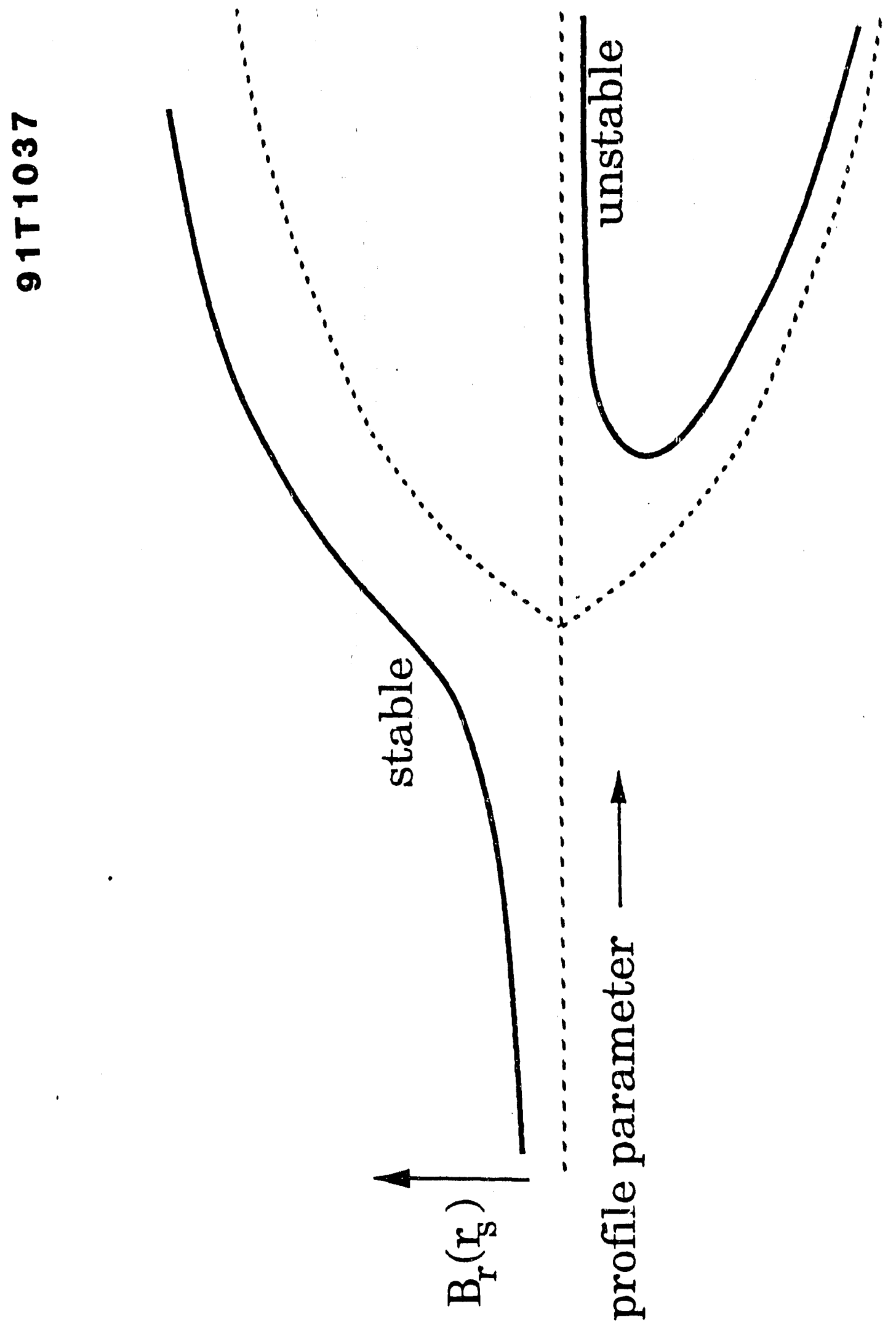


$n$
0
0
1
1
0
0

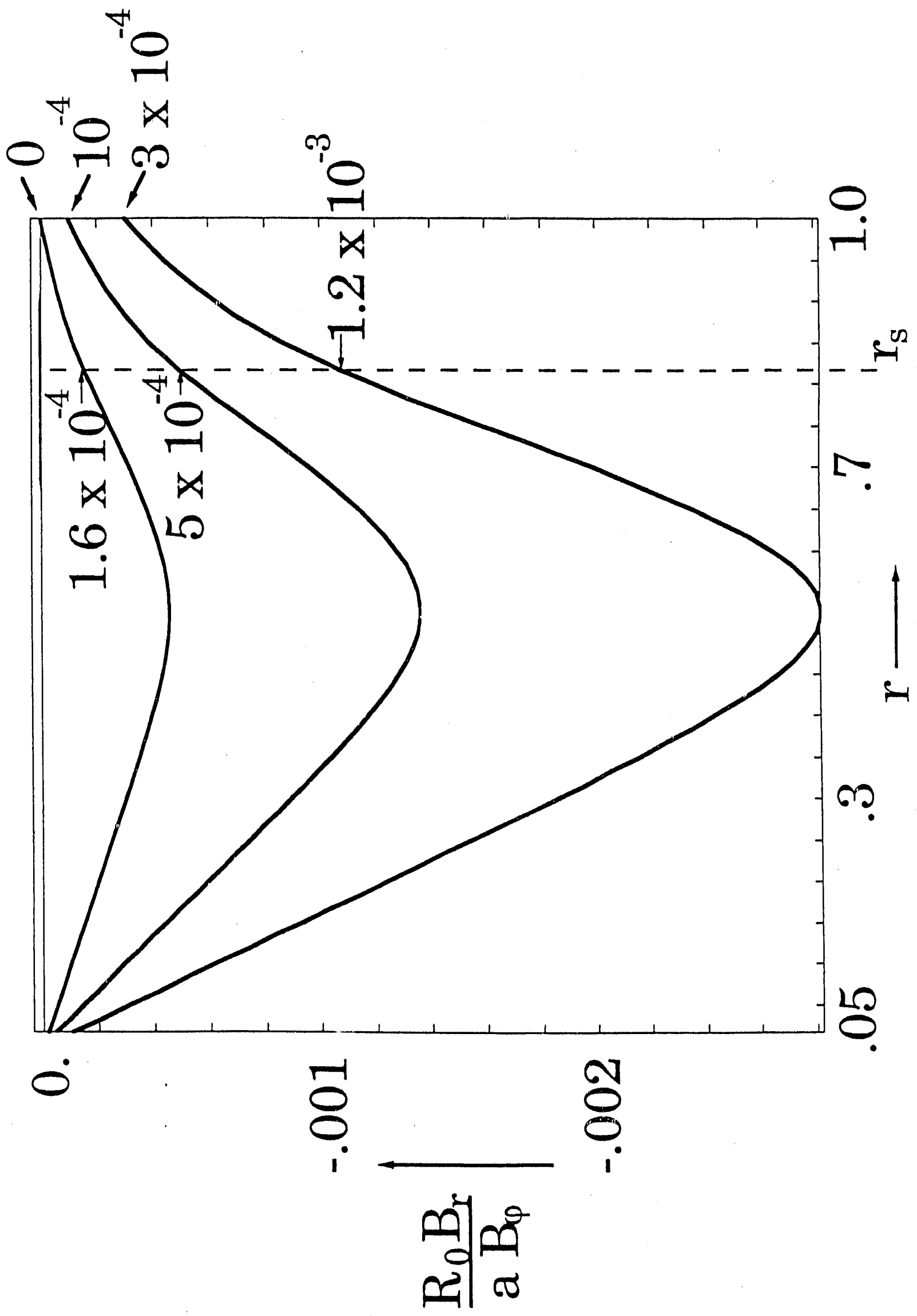




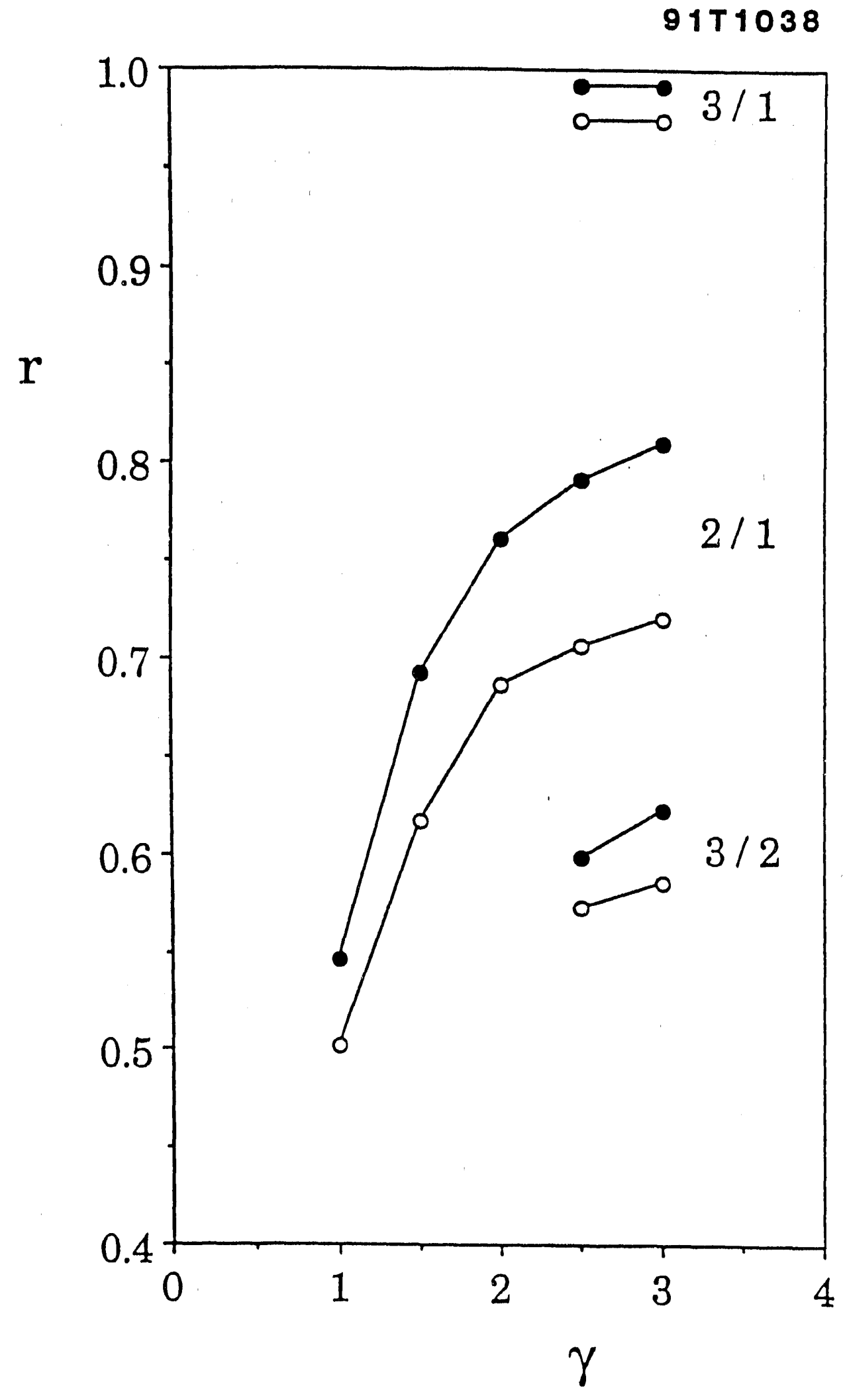

Fig. 4 
$91 T 1039$

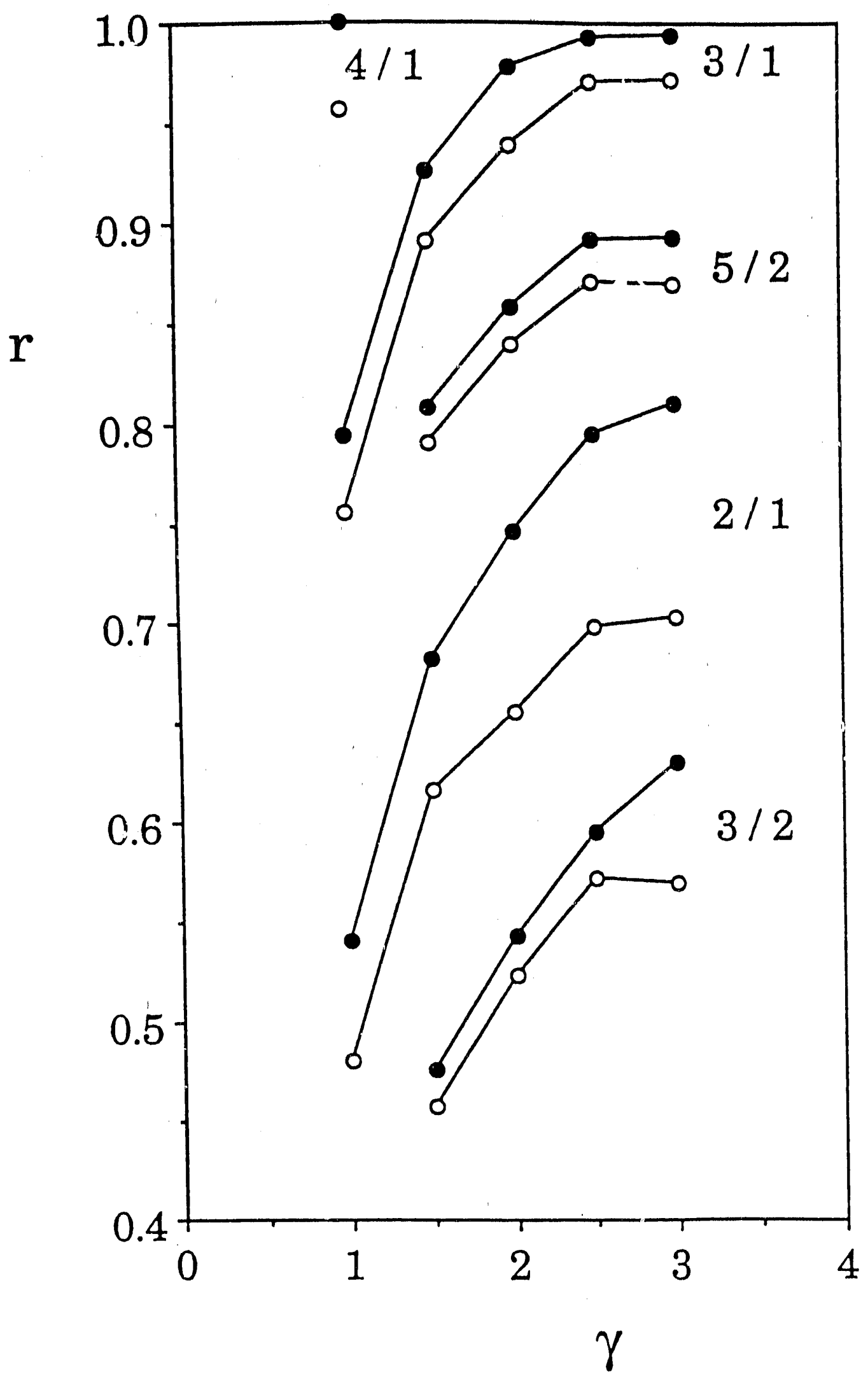

Fig. 5 


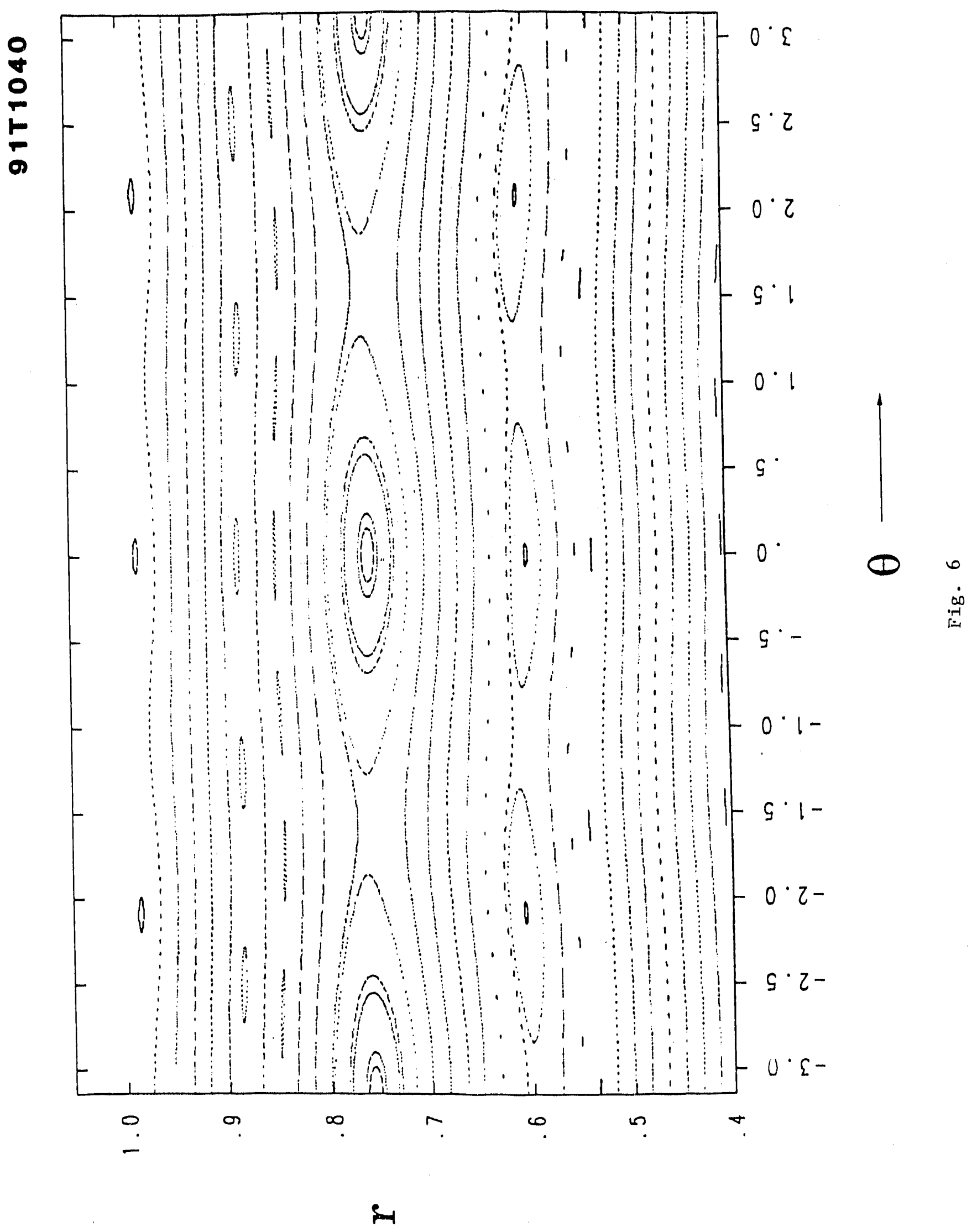




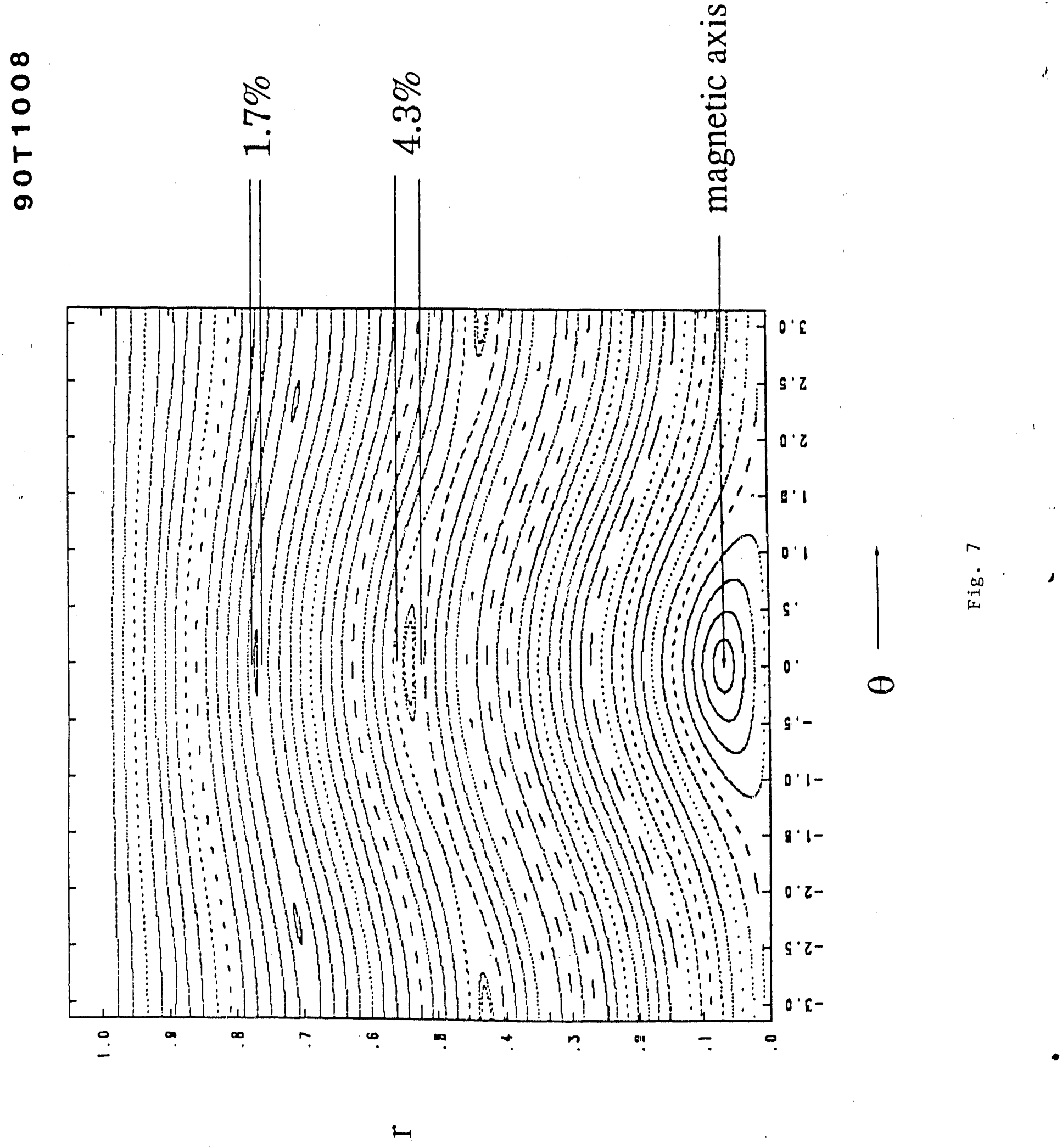




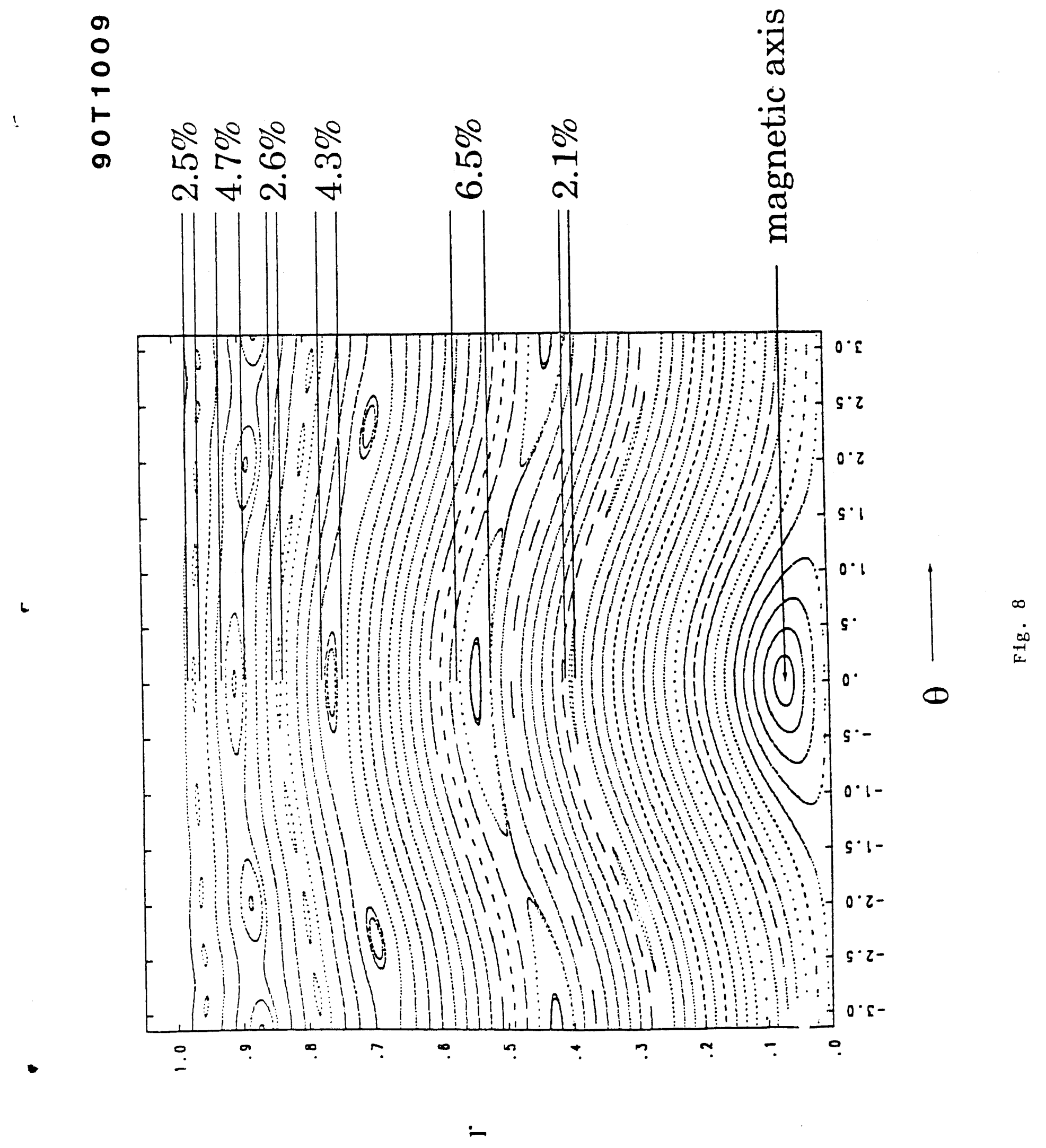


$91 T 1041$

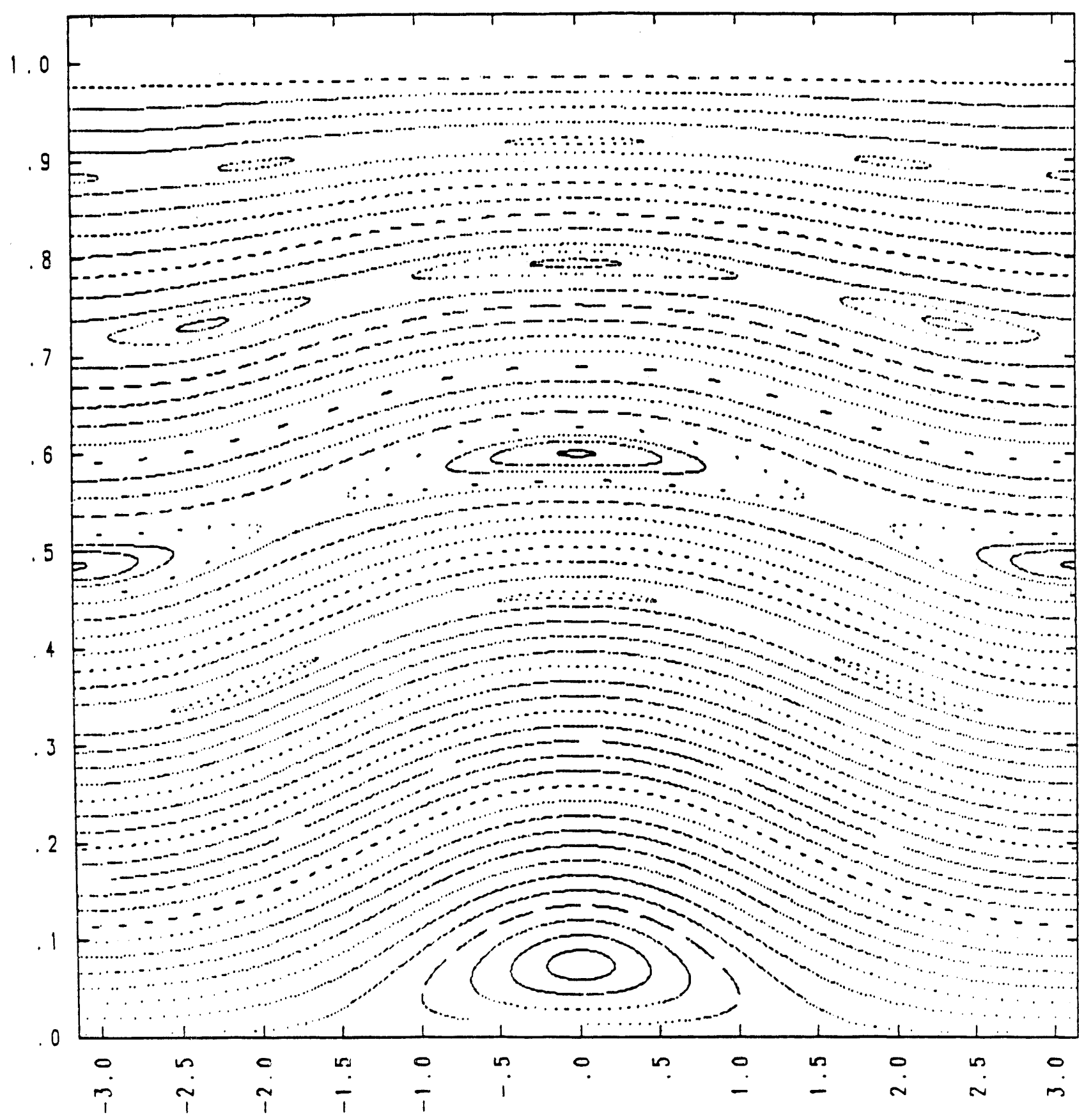

Fig. 9 
$91 \mathrm{~T} 1042$

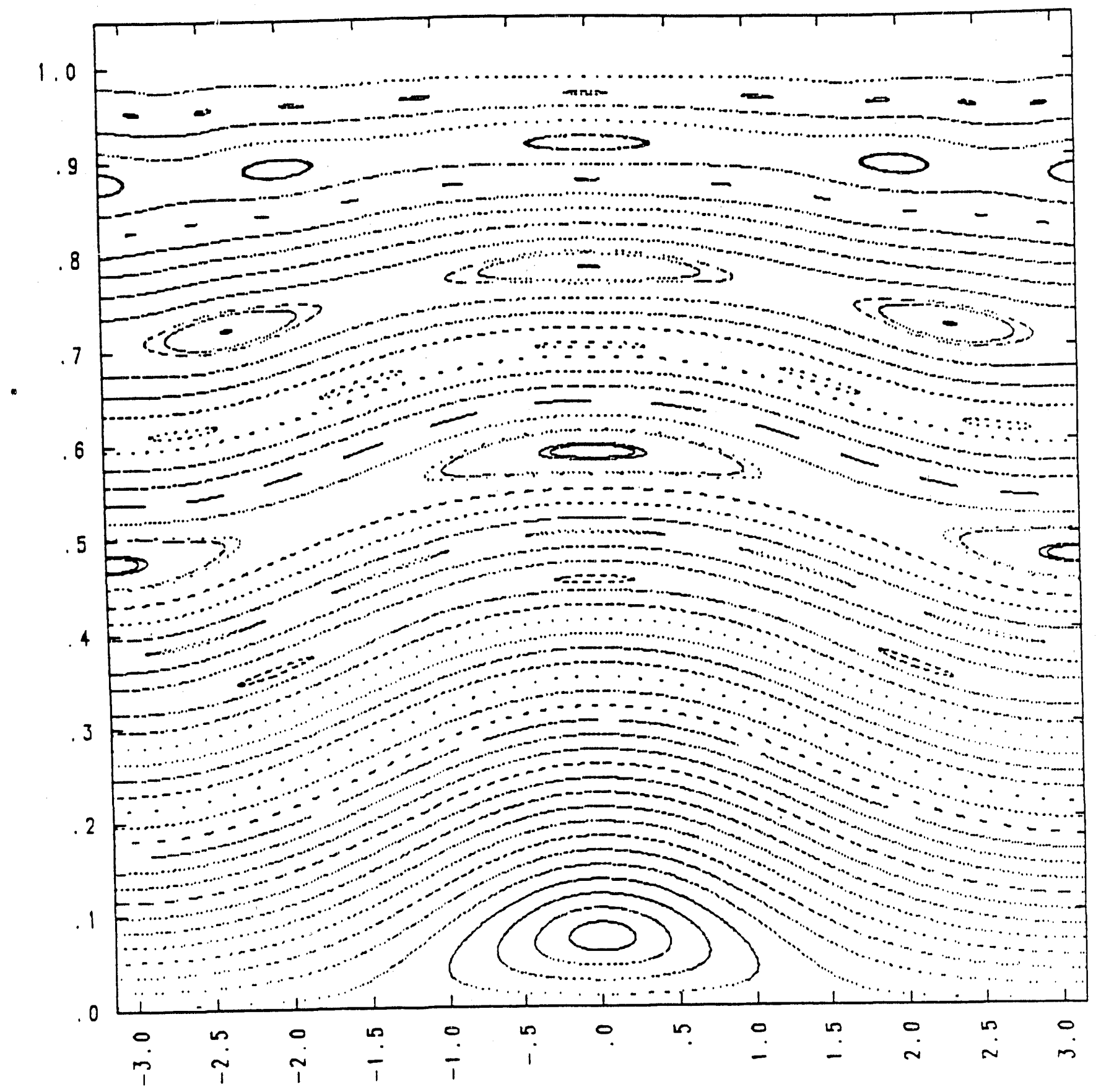

Fig. 10 
Dr. F. Paoloni, Univ. of Wollongong, AUSTRALIA

Prof. M.H. Bronnen, Univ. of Sydnoy, AUSTRALIA

Plasma Research Lab., Australian Nat. Univ., AUSTRALIA

Prot. I.R. Jones, Flinders Univ, AUSTRALA

Prof. F. Cap, Inst. for Theoretical Physics. AUSTRIA

Prot. M. Heindler, Institut for Theoretische Physik, AUSTRIA

Prof. M. Goossens, Astronomisch InstituUt, BELGIUM

Ecole Royale Militaire, Lab. de Phy. Plasmas, BELGIUM

Commission-European, DG. XII-Fusion Prog., BELGIUM

Prof. R. Bouciquie, Rijksuniversiteit Gent, BELGIUM

Dr. P.H. Sakanaka, Institus fo Fisica, BPAZIL

Instituto Do Posquisas Especiais-INPE, BRAZIL

Documents Office. Abmic Enorgy of Canada Lid., CANADA

Dr. M.P. Bectynski, MPB Tectmologies, Inc., CANADA

Dr. H.M. Skarsgard, Univ. of Saskatchowan, CANADA

Prof. J. Teichmann, Univ. of Montreal, CANACA

Prof. S.R. Sreenivasan, Univ. of Calgary, CANADA

Prof. T.W. Johnston, INAS-Energie, CANADA

Dr. A. Bolton, Contre canadien de fusion magnétique, CANADA

Dr. C.R. James., Univ. of Aberta, CANADA

Dr. P. Lukec, Komenskeho Universzita, CZECHOSLOVAKIA

The Librarian, Culham Laboratory, ENGLAND

Library, R61, Rutherford Appletcen Laboratory, ENGLAND

Mrs. S.A. Hutchinson, JET Library, ENGLAND

P. Mahonen, Univ. of Helsinkj, FINLAND

C. Noututh Lab. de Physique des Nilieux lonisés, FRANCE

J. Radet, CEN/CADARACHE - Bat 506, FRANCE

Ms. C. Rinni, Univ. of loannina, GREECE

Dr. T. Munl, Acaderny Bibliographic Ser., HONG KONG

Preprint Library, Hungerien Academy of Sa.. HUNGARY

Dr. B. Das Gupta Saha inst. of Nuclear Physics, INDIA

Dr. P. Kaw, Inst for Plasma Rescarch, INDiA

Dr. P. Rosenau, Isreel Inst of Tectnology, ISPAEL

Librarian, Intemational Center for Theo Physics, ITALY

Miss C. De Palo, Associazione EURATOM-ENEA, ITALY

Dr. G. Grosso, Istituto di Fisica del Plasma, ITALY

Dr. H. Yamato, Toshiba Res a Devel Center, JAPAN

Prof. I. Kawakariri, Atomic Energy Res.Inst, JAPAN

Prof. K. Nishikawa, Hiroshima Univ., JAPAN
Director, Japan Atomic Energy Research Inst., JAPAN

Prof. S. Itoh, Kyushu Univ., JAPAN

Data and Planning Center, Nagoya Univ., JAPAN

Prof. S. Tanaka, Kyoto Univ., JAPAN

Library, Kyoto Univ., JAPAN

Prot. N. Inoue, Univ. of Tokyo, JAPAN

S. Mori, Technical Advisor, JAERI, JAPAN

O. Mitarai, Kumamoto Inst. of "echnology, JAPAN

H. Jeong. Korea Advanced Energy Research Inst., KOREA

Prot. D.I. Choi, The Korea Adv. Inst of Sai. \& Tech., KOREA

Prot. B.S. Liby, Univ. of Waikato, NEW ZEALAND

Inst. of Plasma Physics, PEOPLE'S REPUBLIC OF CHINA

Librarian, Inst. of Physics, PEOPLE'S REPUBLC OF CH!NA

Library, Tainghua Univ., PEOPLE'S REPUBLIC OF CHINA

2. L, S.W. Inat Physics, PEOPLE'S AEPUBUC OF CHINA

Prot. J.A.C. Cabra, Instituto Superior Tecnico, PORTUGAL

Dr. O. Potrus, AL I CUZA Univ., ROMANIA

Dr. J. do Villiers, Fusion Sudies, AEC, S. AFRICA

Prof. M.A. Hellberg, Univ. of Natu, S. AFRICA

C.I.E.M.A.T, Fusion Divizion Library, SPAIN

Dr. L. Stonfio, Univ. of UMEA, SWEDEN

Librery, Royd Inst of Tectnology, SWEDEN

Prof. H. Witholmson, Chaimers Univ. of Tech., SWEDEN

Centre Phys. Des Plasmas, Ecole Polytech, SWITEERLAND

Bibliothoek, Inat. Voor Plasma-Fysica, THE NETHERLANDS

M. Durgut, Vice Chaiman, Middto East Tech. Univ., TURKEY

Dr. D.D. Ryutov, Siberian Branch of Academy of Sxi., USSR

Dr. G.A. Elisegv, Kurchatov Inst, USSA

Librarien, The Ukr.SSR Academy of Sciences, USSR

Dr. L.M. Kovrizhnykh, Inst of Genera Physics, USSR

Kemforsctungsaniage GmbH, Zentrabibliothek, W. GERMANY

Bibliothok, Inst. Für Plasmaforschung. W. GEPMANY

Prot. K. Schinder, Ruhi-Univorsitat Bochum, W. GERMANY

Dr. F. Wagner, (ASDEX), Max-Planck-Institut, W. GERMANY

Librarian, Max-Planck-Institut, W. GERMANY

Prot. R.K. Janev, Inst. of Physics, YUGOSLAVIA 

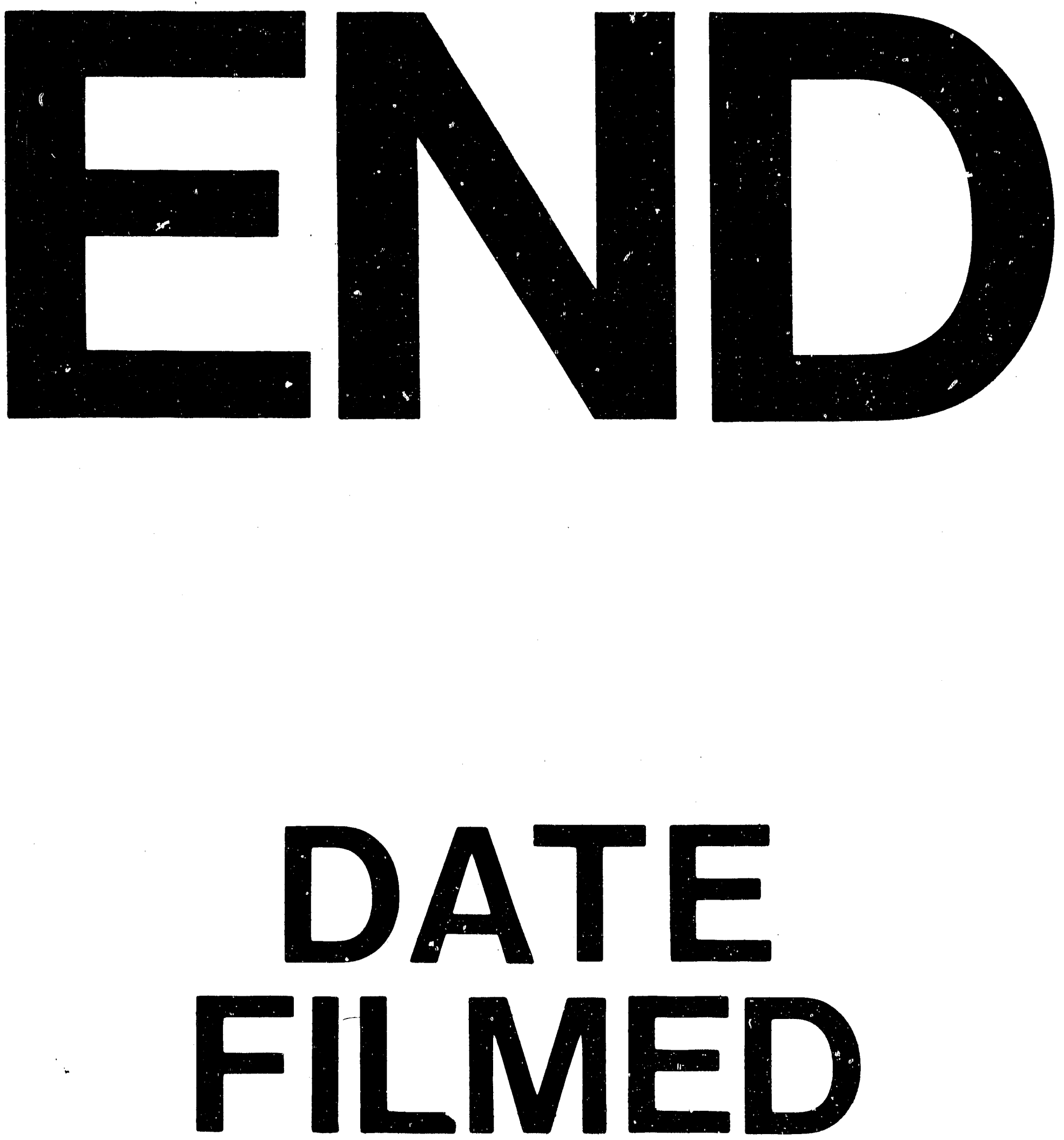

1
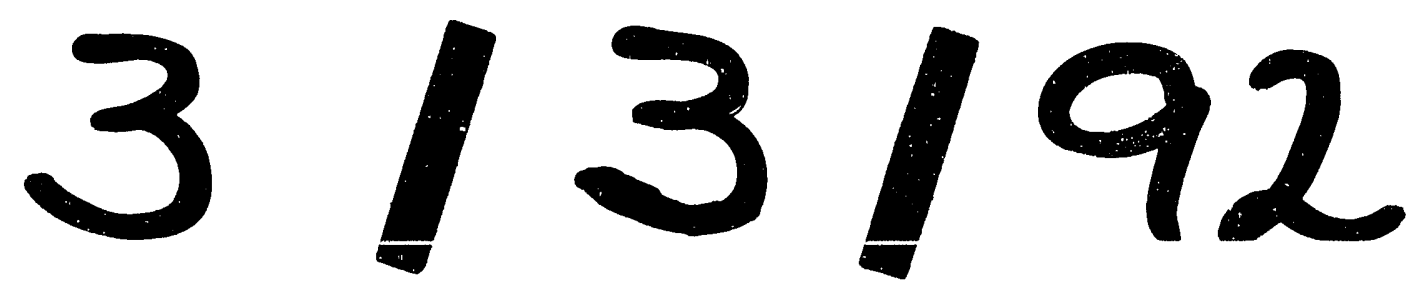


\section{'}

